\title{
Manufacture of the Printed Circuit Boards for Microstrip Transmission Line Circuits
}

\author{
Sudram Arkom ${ }^{1, *}$, Karnna Chayaphon ${ }^{2}$, Chanthong Apirun ${ }^{3}$ and Tantiviwat Sugchai ${ }^{1, *}$ \\ ${ }^{1}$ Faculty of Industrial Education and Technology Rajamangala University of Technology Srivijaya, 1 Ratchadamnoennok Rd, \\ Boryang Sub-district, Muang District, Songkhla 90000, Thailand \\ ${ }^{2}$ Pathumwan Institute of Technology, 833 Rama 1 Road WangmaiPathumwan, Bangkok 10330, Thailand \\ ${ }^{3}$ College of Industrial Technology and Management Rajamangala University of Technology Srivijaya, 99 Thongnien Sub-district, \\ Khanom district, Nakhon SriThammarat, 80210, Thailand \\ ${ }^{*}$ Corresponding author
}

\begin{abstract}
Microstip transmission line circuits play important roles in many microwave communication systems. This paper presents to manufacture of the printed circuit boards (PCB) based on spray etching machines for microstrip transmission line circuits. This is an experimental research with the objectives to analyze implicate variable with low cost PCB spray etching machines and control effect of variable for etching on the PCB. The measured results are in good agreement with the simulated predictions, which can be quite useful for microstrip transmission lines applications in future microwave communication systems.
\end{abstract}

Keywords-PCB; microstrip transmission lines; spray etching; RF planar circuits

\section{INTRODUCTION}

Nowadays printed circuit boards (PCB), also known as microstrip transmission lines, are vastly used in RF circuits and wireless communication systems. The microstrip trans-mission lines are widely used in planar circuits. They can be fabricated by using printed circuit technology and suit for commercial applications due to their small sizes, lower fabrication cost and easy design for microwave integrated circuits [1]. Various kinds of microstripcircuits, including the filters [2-3], multiplexers [4-6], antennas [7-8], power dividers [9-10], and so on have been investigated.

Generally, the main issue of planar circuit design composed of low loss, light weight, compactness, and flexible passband frequencies. Aside from planar circuit design, precise frequency responses are necessary because there still are discrepancies in simulation results. The general procedures for the design process are as follows: 1) the characteristics of circuits were calculated; 2) frequency responses were simulated; and 3) the planar circuits were fabricated and measured. Forcase, the measured results were found not to agree with the simulated responses due to the fact that parameter settings were inconsistent, or manufacturing processes of circuits were not completed (i.e. lack of precise circuit creation and the coarseness of the circuits).

In this paper, printed circuit boards for microstrip transmission line circuits were proposed. They were studied and designed based on the manufacturing of spray etching machines constructed with an experimental research. The objectives of this research were to analyze implicate and to control the effect of variable for etching onto the PCB.

\section{The SpRAy EtChING METHOD}

\section{A. Merging PCB and Dry Film Photoresist Method}

The analysis based on optimization of the merging PCB and dry film photoresist. Equipment in this process consists of fluorocarbon rubber roller and DC motor used for traction PCB, heater infrared used for heating, thermocouple used for measuring temperature and temperature controller used to control temperature. The system was represented in a fully parameterized model; all geometrical features is shown in Fig. I

\section{B. Photolithographymethod}

Photolithography is the process by which patterns on the semiconductor material can be defined using light for transferring pattern on tosubstrate. The PCBs are formed, photolithography has used ultraviolet light while transfers the mask image to the resist coated wafer and activates photosensitive component. Method of photolithography comprises three types of masking are contact printing, proximity printing and projection printing. Equipment in this process consists of UV lamps and time controller used to control delay time on and off operation by using a relay, all geometrical feature is shown in Fig. II

\section{Spray Etching Method}

The etching process is important in the spray etching technology, has been applied to the construction of lead frames. The etching features would depend on the etching system, characteristics of the metal substrate and etching conditions. An aqueous solution of ferric chloride $\left(\mathrm{FeCI}_{3}\right)$ is normally used as the etchant. The objective of this study, we investigated the etching factor is to obtain detailed information for the fabrication of lead frames by using spray technology to wet etching process and control effect of variable for spray etching on the PCB. Equipment of this process consists of temperature control for heat capacity of an aqueous solution of ferric chloride, timer controls processing time for spray etching and spray type machine has a pump, etchant tank, and nozzle, all geometrical feature is shown in Fig. III 


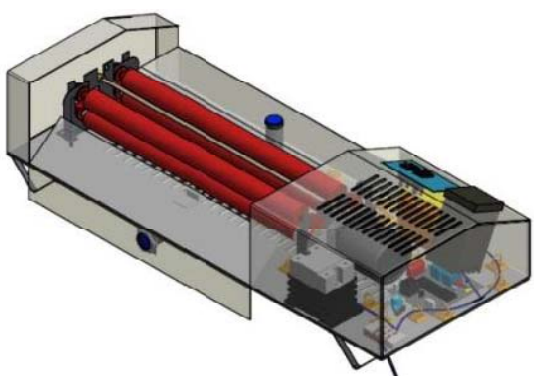

FIGURE I. THE MERGING PCB AND DRY FILM PHOTORESIST MACHINE 3D SCHEMATICS

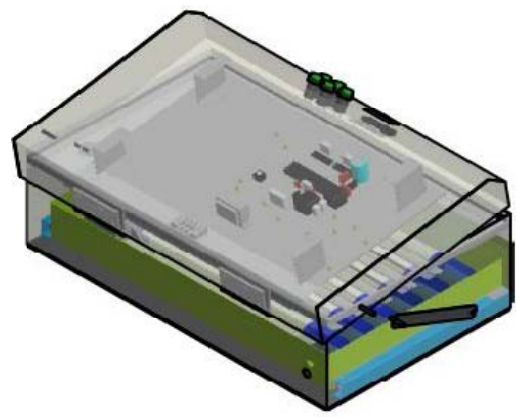

FIGURE II. THE PHOTOLITROGRAPHY GEOMETRICS SHAPES MACHINE 3D SCHEMATICS

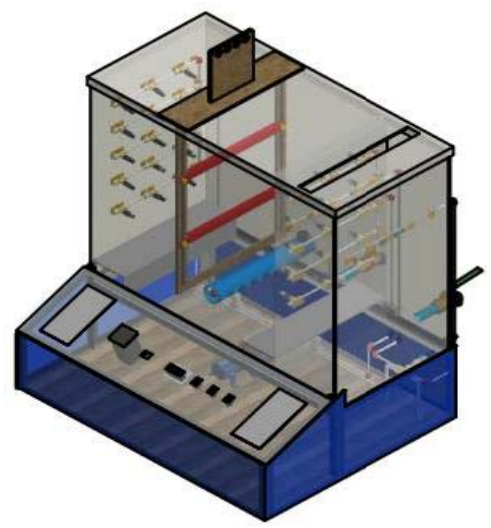

FIGURE III. THE SPRAY ETCHING GEOMETRICS SHAPES MACHINE 3D SCHEMATICS

\section{PROTOTYPe OF SPRAy ETCHING MACHINE}

Based on theoretical in [11-13] considerations a prototype of printed circuit board spray etching machines for fabricationmicrostrip transmission line circuits are shown in Fig. IV., where Fig. IV (a) shows the structure of the proposed merging PCB and dry film photo resist machine, the total size of this machine is $20 \times 60 \times 15 \mathrm{~cm}$., the parameters are designed consist of the temperature is approximately 60-70Celsius, where motor velocity equal $10 \mathrm{rpm}$. In addition the machine can be controlled by controlling for a forward and reward of fluorocarbon rubber roller, Fig. IV (b) shows the structure of the proposed photo-lithography for transferring pattern onto the substrate, the total size of this machine is $35 \times 55 \times 20 \mathrm{~cm}$., the parameters are designed consist of the distance between the lamps and the substrates approximately $10 \mathrm{~cm}$., the amount5 tubes of UV black light $15 \mathrm{~W}$., the time for radiation of UV lamp is 15 Sec. Fig. IV (c) shows the structure of the proposed spray etching machine, the total size of this machine is $50 \times 60 \times 70 \mathrm{~cm}$., the parameters are designed consist of the temperature of boiling the ferric chloride is approximately 5060Celsius by using PID controller, the pressure of pump for spray etching is 11 Bar where the number of nozzles can be chose variation cross-section area of the substrate and the etching machine used time about 1.30 minutes for spraying to circuit design.

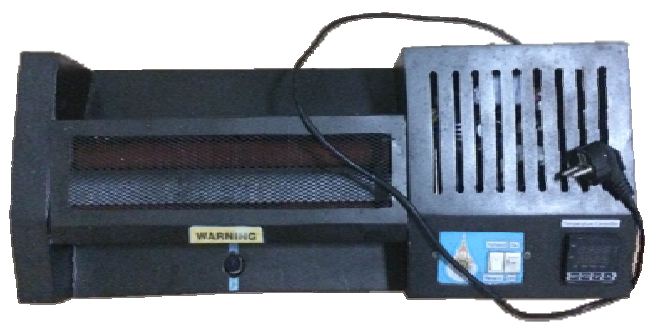

(a)

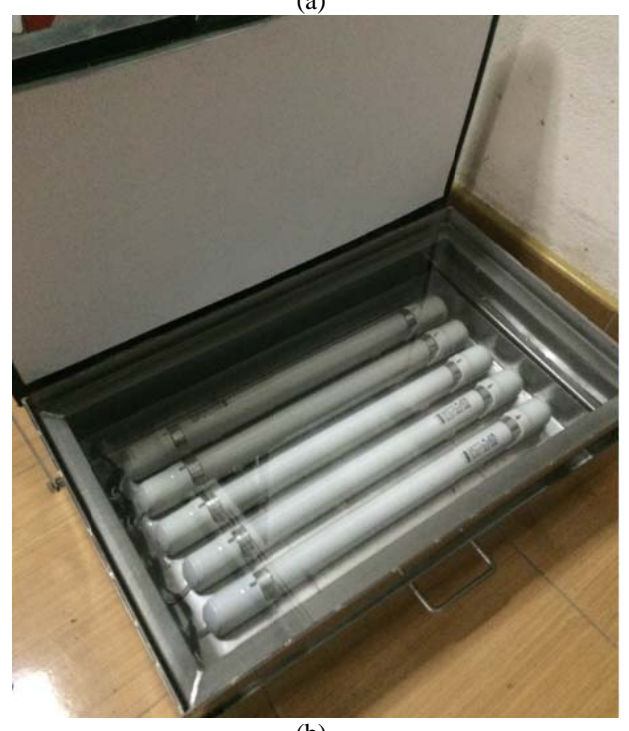

(b)

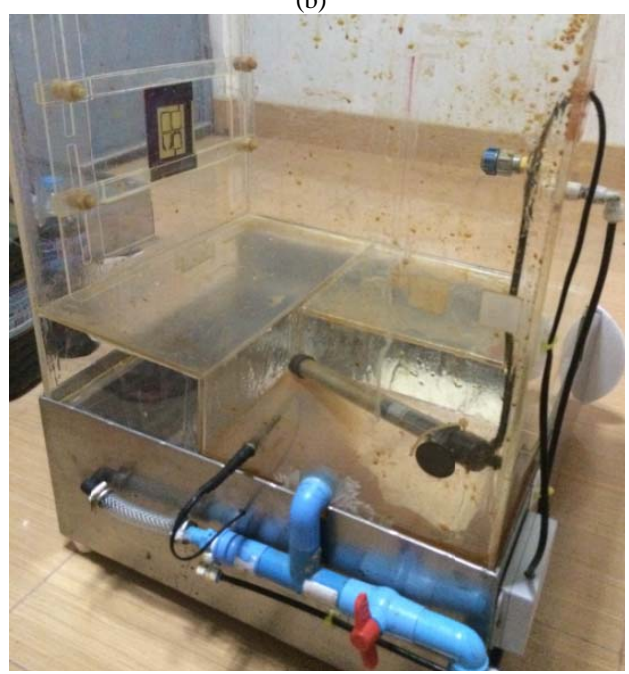

(c)

FIGURE IV. THE PROTOTYPE OF SPRAY ETCHING MACHINES 


\section{RESULTS AND DISCUSSION}

After the machines construct have been completed. For the example, the bandpass filter and triplexer are designed and fabricated as shown in Fig. V. The substrate we used in this workis the Diclad Arlon 880 with a dielectric constant $\left(\boldsymbol{\varepsilon}_{r}\right)$ of 2.2, a thickness of $0.8 \mathrm{~mm}$. and a loss tangent ( $\tan \delta$ ) of 0.0009 .

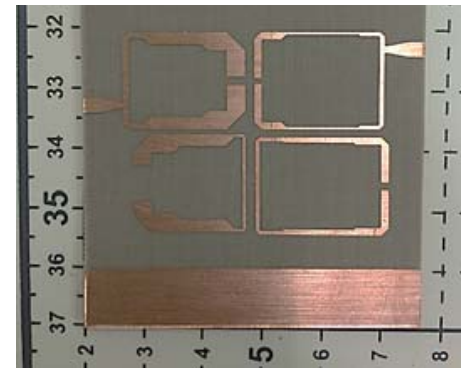

(a) Bandpass filter

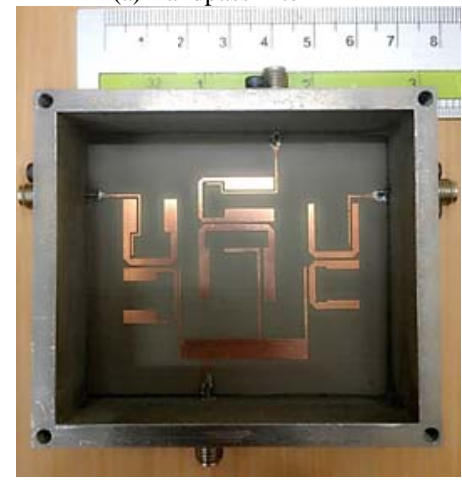

(b) Triplexer

FIGURE V. THE PHOTOGRAPH OF THE FABRICATED MICROSTRIP TRANSMISSION LINES

Fig. V (a) presents a photograph of four pole cross-couple the bandpass filter using tri-section stepped impedance resonators, the total size of the filter is $52 \times 26 \mathrm{~mm}$., the gap between resonator is less about to $0.3 \mathrm{~mm}$. with fundamental frequency $f_{0}$ at $1.5 \mathrm{GHz}$ and fractional bandwidth is $4.65 \%$. The scattering parameter simulation and measurement results are shown in Fig. VI (a), the measurement results show great agreement with simulated results. The accuracy of frequency response can be observed in narrow band response, pass band frequency and two transmissions zero. Moreover the wideband response from 1 to $8 \mathrm{GHz}$ in Fig. VI (b) is good agreement with the full-wave simulation results respectively. Fig. $\mathrm{V}$ (b) presents a photograph of three pole triplexer using stepped impedance resonators, the total size of the triplexer is $68 \times 59$ mm., the gap between resonators is less about to $0.3 \mathrm{~mm}$. The triplexer is operating fundamental frequencies of the three bandpass filters are $2.05,2.45 \mathrm{GHz}$ and $3.50 \mathrm{GHz}$, the fractional bandwidth of the bandpass filters are 4.87\%, $4.08 \%$ and 5.72 \%respectively. The Scattering parameter simulation and measurement results are shown in Fig. VII (a), which the measurement results show great agreement with simulated results. The accuracy of frequency response can be observed with common resonator is complicated designs, multiband of passband frequency response. Moreover the wideband response from 1 to 14 GHzin Fig. VII (b)is good agreement (approximately 1 to $8 \mathrm{GHz}$ ) with the full-wave simulation results respectively.

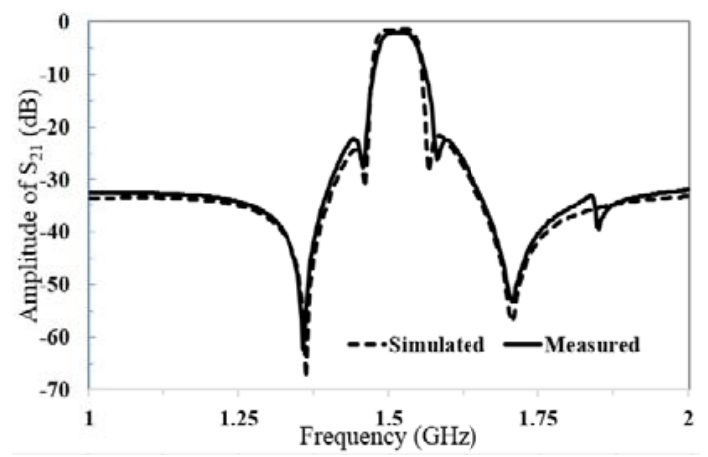

(a)Simulated and measured for passband

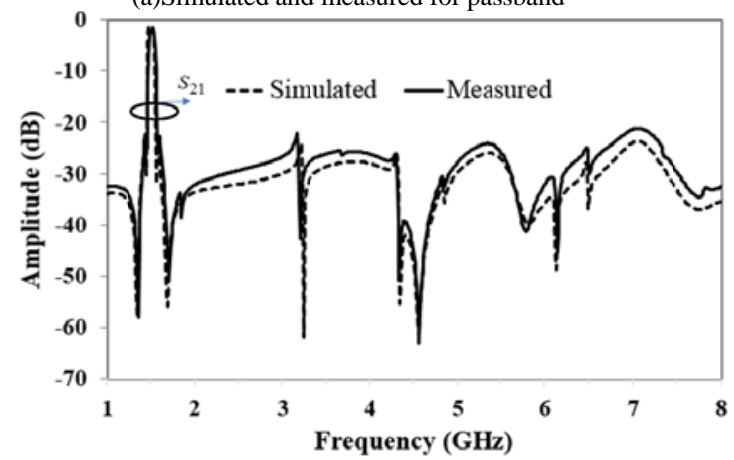

(b) Simulated and measured wideband response

FIGURE VI. SIMULATED AND MEASURED RESULTS OF THE PROPOSED BANDPASS FILTER

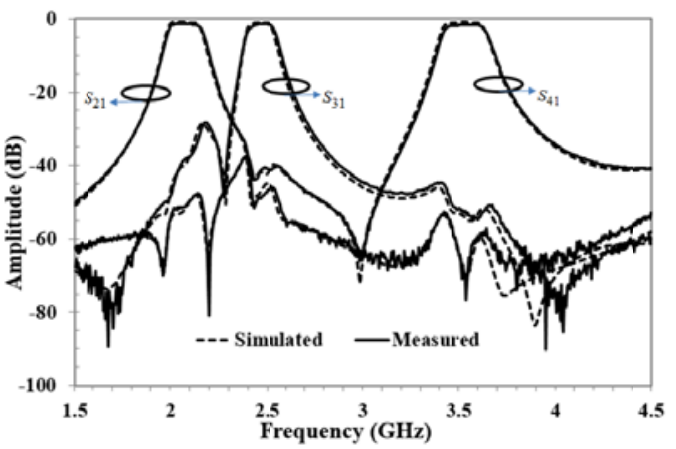

(a)Simulated and measured for passband

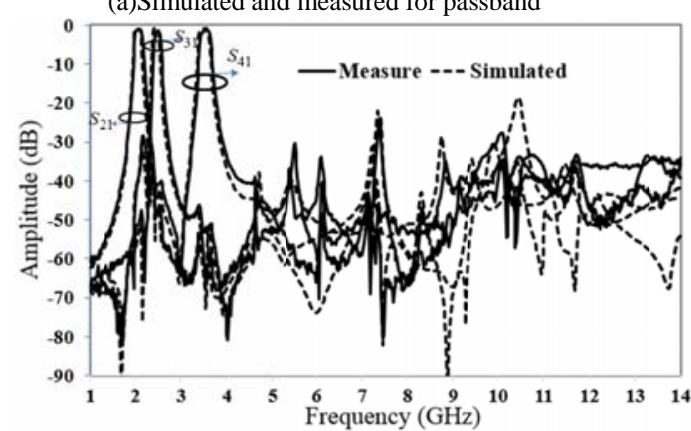

(b)Simulated and measured wideband response

FIGURE VII. SIMULATED AND MEASURED RESULTS OF THE PROPOSED TRIPLEXER 


\section{CONCLUSION}

The paper presented three simple of low cost spray etching machines for micro strip circuit fabrication. The vital parameters were involved in these three processes. In the following process: 1) Merging PCB and dry film photo resist process are speeded motor and temperature ;) Photolithography process are light intensity and timer controller; 3) Spray etching process are temperature for boiling an aqueous solution, pressure for spraying and timer controller. The proposed bandpass filter and triplexer are designed using PCB spray etching machines. The measured and simulation responses agree well with each other and show that good passband responses and upper stopband attenuation can be achieved simultaneously.

\section{REFERENCES}

[1] Hong, J.S., Microstrip Filters for RF/Micowave Applications, 2nd Ed., New Jersey, Wiley, 2011.

[2] M. Jiang, L.-M. Chang and A. Chin, "Design of Dual-Passband Microstrip Bandpass Filters with Multi-Spurious Suppression,” IEEE Microwave and Wireless Components Letters, vol. 20, no. 4, pp. 199-201, April. 2010.

[3] Hong, J.-S., H. Shaman and Y.-H. Chun, "Dual-mode Microstrip Openloop Resonators and Filters,” IEEE Trans. Microwave Theory Tech., Vol. 55, No. 8, 1764-1770, Aug. 2007.

[4] P. H. Deng, M. I. Lai, S. K. Jeng and C. H. Chen, "Design of Matching Circuits for Microstrip Triplexers Based on Stepped-impedance Resonators,” IEEE Trans. Microwave Theory Tech., vol. 54,no. 12, pp. 4185-4192, Dec. 2006.

[5] T. Yang and G. M. Rebeiz, "Three-pole 1.3-2.4-GHz Diplexer and 1.12.45-GHz Dual-band Filter with Common Resonator Topology and Flexible Tuning Capabilities,” IEEE Microwave and Wireless Components Letters, vol. 61, no. 10, pp. 3613-3624, Oct. 2013.

[6] X. Guan, F. Yang, H. Liu and L. Zhu, "Compact and High-Isolation Diplexer Using Dual-Mode Stub-Loaded Resonators, ” IEEE Microwave and Wireless Components Letters, vol.24, no.6, pp.385-387, June 2014.

[7] M. Ojaroudi, G. Ghanbari, N. Ojaroudi and C. Ghobadi, "Small Square Monopole Antenna for UWB Applications with Variable Frequency Band-Notch Function,” IEEE Antennas and Wireless Propagation Letter, vol. 8, pp. 1061-1064, August 2009.

[8] M. Sun, Y. P. Zhang and Y. Lu, "Miniaturization of Planar Monopole Antenna for Ultrawideband Radios,” IEEE Transactions on Antennas and Propagation, vol. 58 no. 7, pp. 2420-2425, July 2010.

[9] H. Oraizi and A. R. Sharifi, "Optimum Design of Asymmetrical Multisection Two-Way Power Dividers With Arbitrary Power Division and Impedance Matching, ” IEEE Trans. Microwave Theory Tech., vol. 59, no. 6, pp. 1478-1490, June 2011.

[10] C. F. Chen, T. Y. Huang, T. M. Shen and R. B. Wu, "Design of Miniaturized Filtering Power Dividers for System-in-a-Package,” IEEE Transactions on Components, Packaging and Manufacturing Technology, vol. 3, no. 10, pp. 1663-1672, Oct. 2013.

[11] Ji-Won Jung, "Experimental Study on Spray Etching Process in Micro Fabrication of Lead Frame,”KSME International Journal, vol. 18, No. 12, pp. 2294-2302, Sep. 2004.

[12] J.W.Jung, Y.J. Kim and D.J.Kim,“Correlation Between Spray Characteristics and Etching Characteristics in Twin Spray,” Trans. of KSME (B), Vol. 28, No. 4, pp. 449-455, 2004.

[13] G. Zhou, W. He, S. Wang, Y. Mo, K. Hu and B. He, "A Novel Nitric Acid Etchant and Its Application in Manufacturing Fine Lines for PCBs," IEEE Transactions on Electronics Packaging Manufacturing, vol. 33, no. 1,pp. 25-30, Jan. 2010. 